\title{
Making the most of game theory in the supplier selection process for complex items
}

\author{
Miguel Mediavilla ${ }^{\mathrm{a}-\mathrm{b}^{*}}$, Kepa Mendibil $^{\mathrm{c}}$ and Carolina Bernardos ${ }^{\mathrm{d}}$
}

${ }^{a}$ Department of Mechanics and Industrial Production, University of Mondragon, Mondragon, Spain; ${ }^{b}$ Deusto Business School, University of Deusto, San Sebastian, Spain; ${ }^{c}$ University of Strathclyde, Glasgow, Scotland; ${ }^{d}$ Department of Economic Analysis, University of Zaragoza, Zaragoza, Spain

*Miguel Mediavilla Guisasola,

c/ Alfonso X El Sabio 4-5C

E-50006 Zaragoza (Spain)

miguel.mediavilla@gmail.es

Kepa Mendibil

University of Strathclyde

Design, Manufacturing and Engineering Management

G11XJ Glasgow

United Kingdom

kepa.mendibil@strath.ac.uk

Carolina Bernardos

c/ Fray Luis Amigo 8-12C

E-50006 Zaragoza (Spain)

carolber81@yahoo.es 


\section{Making the most of game theory in the supplier selection process for complex items}

It is widely accepted that strategic purchasing plays a critical role on competitive advantage and it is in this context that there has been a growing interest in the application of the principles of game theory to enhance the impact of supplier selection processes. Up until now these applications have been mainly focused on commodity products and scholars have recently called for further research into the use of game theory to develop supplier selection processes for more complex products. In addition, current research suffers from a lack of insights from practical applications in industry and existing knowledge on the design characteristics, implementation and impact of these supplier selection models is still limited. The aim of this paper is to contribute to this debate by discussing the design and implementation of a novel supplier selection process based on the principles of game theory through an empirical study of a construction project for an automotive organisation. The novelty of this research stems from the application of game theory to design and implement a two-phase supplier selection process, combining a modified Japanese-auction with a structured bargaining process, and evaluating its impact in the context of complex items. Findings suggest that the application of a two-phase process can enhance the effectiveness of the supplier selection by increasing competition between suppliers and generating better predictions of the outcomes from the negotiation.

Keywords: Supplier selection, game theory, reverse auction, bargaining, complex items 


\section{The managerial and academic challenge}

'How can we leverage competition amongst suppliers?' This is a question often asked by managers across industry when developing and deploying purchasing strategies. This challenge is not new to industry given that it is widely accepted that purchasing can significantly improve sales margins, drive substantial cost savings and give firms a competitive advantage (Van Weele 2009; Monczka and others 2008). As a result, purchasing practitioners continuously work on strategies, policies and practices to operationalise purchasing objectives (e.g. cost reduction, quality improvement, increased value add) that contribute to the overall business success (Van Weele 2009).

At a strategic level, industry has widely adopted particular frameworks (e.g. Kraljic 1983) to support category management and purchasing portfolio activities (Gelderman and Van Weele 2005a; Monczka and others 2008; Tassabehji 2010). Whilst the use of some of these frameworks can help purchasing practitioners in developing suitable strategies, the deployment of specific purchasing strategies and practices remains a challenging task that requires careful analysis by experienced purchasing professionals (Kang et al. 2018).

This tactical purchasing process is also know as supplier selection process, and is considered a core contributor to firm performance (Krause, Pagell, and Curkovic 2001) and, at the same time, a potential source of complex and difficult decision making challenges (Weber, Current, and Benton 1991; Huang and Keskar 2007; Yigin et al. 2007; Seth et al. 2018). Supplier selection processes can benefit from the application of Total-Cost-of-Ownership (TCO), an estimation of all direct and indirect costs associated with a specific procurement object over its entire life cycle. TCO has been commonly used as a decision-making tool for the suppliers' offer evaluation and selection (Weber and Ellram 1993; Alard et al. 2009; Mandolini, Marilungo, and Germani 2017). 
Departing from the basis that supplier selection is a critical process within purchasing management and requires innovative approaches to increase the impact on firm performance, this paper argues that using game theory, and more specifically combining auctioning and bargaining methods, can enhance the effectiveness of the supplier selection process for complex items. Evidence from the literature shows that there is limited knowledge about the design and application of supplier selection processes based on game theory (Hawkins, Randall, and Wittmann 2009; Tassabehji 2010; Schoenherr et al. 2012; Spina et al. 2013) with the existing research being simply descriptive or prescriptive in nature. This is particularly evident in the context of complex projects and highly customised goods (Aital, Pawar, and Behl 2017; Schoenherr 2019).

Despite of the challenges for adopting and diffusing electronic procurement systems and practices (Toktaş-Palut et al. 2014; Yu et al. 2015; Ramkumar, Schoenherr, and Jenamani 2016; Brandon-Jones and Kauppi 2018; Srai and Lorentz 2019), innovations in digital technologies have enabled a significant growth of (electronic) reverse auctions over the last two decades. Reverse auctions include characteristics of game theory and are often used to increase competition during the supplier selection process. These applications have been mainly in the context of commodity products and some scholars have recently called for further research into the use of reverse auction in the procurement of more complex products and services (Aital, Pawar, and Behl 2017; Schoenherr 2019; Fugger, Katok, and Wambach 2019).

Even where there is a clear interest in the industry to apply reverse auction, the literature review of Giunipero et al. (2019) found that reverse auction have been 'extensively studied in the two five-year periods running from 2000 to 2009 . However, this activity ceased from 2010 forward' (p. 10). Tassabehji (2010) stated that 'the study 
of reverse auctions is still in the early stages and there remains a dearth of substantial empirical research and much more to uncover'. Research is particularly limited in relation to the application of combined auctioning and bargaining methods (both of which often include features of game theory), with little evidence of empirical research having been conducted to test their application and impact across industry.

The aim of this paper is twofold. First, using an action research study, it provides new insights about the use of game theory in the design and application of a two-phase supplier selection process that integrates auction and bargaining methods. Second, it provides evidence of the (positive) impact that an integrated auction and bargaining method can have on the effectiveness of the supplier selection processes for complex projects. The context of application is the construction project of a new industrial facility for a Spanish automotive company in Mexico.

\section{Game theory and its application to supplier selection}

To review the literature on the application of game theory in supplier selection processes search terms such as "electronic reverse auction", "supplier selection", “supplier awarding”, “e-procurement”, "bidding event”, “e-sourcing”, “online bidding”, "game-theory" and "bargaining" were combined and used across several databases (Inform/ProQuest, EBSCO Host, and Science Direct). This resulted in a core list of articles with additional sources being identified by tracing the references included within these articles (Webster and Watson 2002). This process continued until reaching the point at which further searches yielded no additional studies addressing relevant issues in the field. The analysis of the final list of references showed that a limited number of previous studies were based on empirical work that described and analysed the practical application of reverse auctions and bargaining methods in an industrial context. 
Starting in the 1950s game theory gained much popularity as a field of study and is now an important methodology for researchers in many disciplines, including economics, business, mathematics, political science, biology, psychology, philosophy or law (Gibbons 1997; Maschler, Solan, and Zamir 2013). Game theory is used during situations in which 'players' have conflicting interests and can therefore be defined as 'the study of multiperson decision problems' (Gibbons 1997).

Game theory often refers to 'a set of analytical tools designed to help us understand the phenomena that we observe when decision-makers interact, assuming that decision-makers pursue well-defined exogenous objectives (they are rational) and take into account their knowledge or expectations of other decision-makers' behaviour (they reason strategically)' (Osborne and Rubinstein 1994; Dutta 1999). These interactions are also called 'games' and are a 'description of strategic interactions that includes the constraints on the actions that the players can take and the players' interests, but does not specify the actions that the players do take' (Osborne and Rubinstein 1994). Games are played by a set of rules (Dutta 1999), which specify who is playing (players), what they are playing with (strategies or choices available), when each player gets to play (what is the order) and how much they stand to gain or lose (payoffs). The games can be classified depending on three dimensions (Osborne and Rubinstein 1994; Dixit and Skeath 1999):

(1) Non-cooperative vs. cooperative games: the unit of decision is an individual player (non-cooperative games) or a coalition of individuals (cooperative games). During cooperative games individual participants collaboratively work of activities. On the contrary, when collaboration between participants cannot be enforced and individual participation must be allowed so that participants act solely based on the own interest, then these games are called non-cooperative. 
(2) Strategic vs. Extensive games: this relates to the timing of decision making, with players making decisions simultaneously (strategic games) or consecutively (extensive games). The choice of sequential or simultaneous decision making when designing the game has an important impact on the type of interactive thinking required (Osborne and Rubinstein 1994; Dixit and Skeath 1999). For example, in a sequential game player's decisions are governed by assumptions of the future consequences ("If I do this, how will my opponent react?"). On the other hand, simultaneous decision-making forces players to concurrently figure out their opponents' potential decisions.

(3) Perfect vs. Imperfect information: players could have full information about each other's decisions (perfect information) or not (imperfect information). Perfect information exists when there are no internal or external uncertainties in the game. If any uncertainty exists, the players will make decisions based on imperfect information.

Any given game has solutions that are described as 'a systemic description of the outcomes that may emerge in a family of games' (Osborne and Rubinstein 1994). In that sense, game theory suggests reasonable solutions for classes of games and examines their properties. Game theory may be used for explanation, prediction or prescription in various circumstances (Dixit and Skeath 1999). Mechanism Design Theory is an evolution of game theory and goes a step further by selecting the optimal rules of the game (Börgers 2015; Schulze-Horn et al. 2018). Based on the above, this paper argues that if a buyer is able to design a supplier selection process with several qualified suppliers (players) that compete in a predefined process (order) in order to win a pre-established award (payoff), then the possible decisions by suppliers (strategies or choices) can be influenced by the buyer's interest. 
As a field of research within game theory, bargaining theory is focused on explaining how a surplus (generated in every economic transaction) will be divided by predicting the price of a transaction. If there is more than one course of action and there is a degree of conflict over which course of action to pursue, some form of negotiation to resolve the conflict is necessary (Osborne and Rubinstein 1994). A special bargaining situation occurs when one of the parties holds an auction among competing negotiation partners. This is called theory of auctions, a game with incomplete information and one of the most successful applications of game theory. These theories are related to the supplier selection process by two generic approaches identified within the literature: negotiation and auctioning (also known as competitive bidding) (Monczka and others 2008; Van Weele 2009). Bargaining theory (typically applied to negotiations) and auction theory are based on the principles of game theory and they aim to promote cooperation or competition between suppliers to enhance the results of the supplier selection process.

While the promotion of cooperation with suppliers is a common topic in the private sector (Zimmermann and Foerstl, 2014), regulatory frameworks make strategies based on collaboration, trust and shared risks difficult to implement in public procurement (Tadelis 2012). Public sector organisations are increasingly budget-driven, simultaneously aiming for multiple goals (competitive prices, transparency and prevention of irregularities and corruption), and less concerned about market innovation (Stentoft Arlbjørn and Vagn Freytag 2012), which has led to the promotion of competition based procurement approaches (e.g. using electronic reverse auction).

Competition based strategies however are not exclusive to the public sector and have has been widely used as part of competitive bidding across both sectors usually by means of reverse auctions. (Tatsiopoulos 2004; Tassabehji 2010; Wyld 2011; 
Chaturvedi, Beil, and Martínez-de-Albéniz 2014; Stentoft Arlbjørn and Vagn Freytag 2012). Nonetheless, the pros and cons of competitive negotiations have being ardently discussed in the literature. A usual critic is the potential damage that auctions can have on buyer-seller trust and relationship (key to promote collaboration or cooperative relations), or the suspicion of opportunism (Jap, Sandy 2002; Jap, Sandy D. 2003; Carter and Stevens 2007; Emiliani and Stec 2005).Other works, on the contrary, had concluded that reverse auction does not necessarily affect the supplier cooperation or long-term relationship (Pearcy, Giunipero, and Wilson 2007; Daly and Nath 2005).

In the practice, reverse auctions allow buyers to communicate the purchasing requirements and select the best options from a list of potential suppliers (Mithas, Jones, and Mitchell 2008; Anandalingam, Day, and Raghavan 2005). The most common way for deploying reverse auctions is to allow qualified suppliers to bid in auctions (Chaturvedi, Beil, and Martínez-de-Albéniz 2014). These auctions can be based on strategic games (e.g. sealed bid auctions) or extensive games (e.g. Dutch, English or Japanese auctions) and are mostly non-cooperative and with imperfect information (Table 1).

\begin{tabular}{|l|l|l|}
\cline { 2 - 3 } \multicolumn{1}{c|}{} & \multicolumn{1}{c|}{ Second price logic } & \multicolumn{1}{c|}{ First price logic } \\
\hline OPEN & $\begin{array}{l}\text { Reverse English or } \\
\text { Japanese Auctions } \\
\text { The price decreases (in the } \\
\text { Japanese done by } \\
\text { auctioneer) until one } \\
\text { bidder is left. Bidder is } \\
\text { paid the last bid's price. }\end{array}$ & $\begin{array}{l}\text { Reverse Dutch Auction } \\
\text { Auctioneer increases price } \\
\text { until a bidder accepts. } \\
\text { Bidder is paid the } \\
\text { accepted price }\end{array}$ \\
\hline $\begin{array}{l}\text { SEALED BID } \\
\text { AUCTIONS }\end{array}$ & $\begin{array}{l}\text { Second Price Sealed Bid } \\
\text { Auctions (Vickrey's) } \\
\text { All bidders submit an } \\
\text { offer. Lowest offer wins; } \\
\text { winner receives second } \\
\text { lowest price submitted }\end{array}$ & $\begin{array}{l}\text { First Price Sealed Bid } \\
\text { Auction } \\
\text { All bidders submit an } \text { Lowest offer wins; } \\
\text { offer } \text { winner receives lowest } \\
\text { price submitted }\end{array}$ \\
\hline
\end{tabular}


Table 1. Overview of basic (reverse) auction forms adapted from Milgrom and Weber (1982)

Companies apply auctions to regular negotiations in order to achieve best supply market pricing, reduce award cycle time, increase bidding transparency, enhance price visibility and improve operational performance (Bartezzaghi and Ronchi 2005; G. Hawkins et al. 2014). These processes make the competition harder 'since the performance of the supplier and the price become transparent for all' (Hvolby, Trienekens, and Steger-Jensen 2007).

Previous applications of reverse auctions have been mainly limited to the purchasing of commodities and scholars have recently called for further research to study if reverse auctions are suitable only for commodities or complex and highly customised items can also be put up for bidding (Aital, Pawar, and Behl 2017). In the context of the construction sector, Hanák and Šelih (2017) highlighted the complexity and specificities of construction projects as key factors behind the limited research on the application of reverse auctions. Following from this, Schoenherr (2019) argued that reverse auctions can be applied to complex and highly engineering goods if the specifications are well understood and developed in detail. Fugger, Katok, and Wambach (2019) also believe that reverse auctions are scarce for complex items, since it is often not possible to write complete contract. Two previous works from the authors have provided some real-world evidences to the call: for example, Mediavilla and his colleagues presented a game-theory based bargaining in the electronics \& drives sourcing for harbour cranes sector (Mediavilla, Mendibil, and Rivera 2019) and analysed the application of product engineering methods for enhancing game-theory usage in supplier selection processes for complex items (Mediavilla et al. 2020).

A more recent adaptation of the application of game theory in supplier selection processes is the combination of auctioning and bargaining methods where "net cost 
efficiencies obtained from running a two-stage process versus just a RA can run into significant improvements' (Tunca and Wu 2009). Additionally, there is evidence that reverse auctions that are designed using a multi-attribute approach (i.e. combining 'price' with other factors) can result in superior performance (Pham et al. 2015), especially when these are aligned with the wider category management strategies (Gelderman and Van Weele 2003). A two-phase approach should be more suitable to scenarios with complex attributes, enabling the buyer to get more information and therefore develop a stronger power position over the course of the negotiation (Tunca and Wu 2009; Huh and Park 2010). Huh and Park (2010) demonstrated through an analytical model that the combined auction-bargaining model produced higher profits for the buyer than the standard auction or bargaining models but the literature on the analysis of such models is rather limited (Engelbrecht-Wiggans and Katok 2006; Huh and Park 2010). A criticism of these studies is the fact that they are based on simulation models, which significantly constrains the transferability of the findings to a business context. Also, although the use of a two-phase process is commonplace in complex purchasing scenarios, little is known about the impact of this approach when the second stage (bargaining) follows a predetermined set of rules based on game theory.

Whilst is it widely accepted that reverse auctions save organizations time and money in their purchasing negotiation, there is limited literature discussing the specific reasons behind this success (Wyld 2011). Several authors (Mithas, Jones, and Mitchell 2008; Tassabehji 2010; Schoenherr et al. 2012; Hsin Chang, Tsai, and Hsu 2013) highlight the need for developing more robust theories in this field and emphasise that current research suffers from a lack of insights from practical applications in industry. Hsin-Chang et al. (2013) stated that 'for academics, [reverse auctions] is an emerging phenomenon in the business world, and it needs to be systematically analyzed' with 
Schoenherr et al. (2012) arguing that 'as with any emerging and evolving field... there is a need to develop theories in future research concerning the adoption, implementation, and utilisation of [reverse auctions]'.

The review of the literature shows that previous studies have largely been either simply descriptive or prescriptive in nature (Wagner and Schwab 2004; Schoenherr et al. 2012), which suggests that this field of research might have been constrained by limited collaboration between academics and purchasing professionals who could have access to rich sets of empirical data. Mithas \& Jones (2007) admit that even when auctioneers conducting reverse auctions could have a wealth of data, its proprietary nature makes accessing this data for research purposes a constant challenge that affects the ability to refine current knowledge on the design and deployment of auctions.

The work presented in this paper aims to contribute to current knowledge on the application of game theory in the supplier selection process by tackling two interrelated research gaps identified in the literature. These are the need (1) to further study the application of auctions in the context of complex projects and (2) to empirically evaluate the effectiveness of combined auction-bargaining models in supplier selection processes. Therefore, we propose the following research question:

Can the application of game theory, coupled with a two-phase process including a modified auction model, enhance the outcomes of the supplier selection process for complex projects?

The review of the literature demonstrates that generating new understanding on the application of game theory in supplier selection would also be of great interest to purchasing practitioners since '(they) did not always know the rationale for the choice 
of parameters or how that might have affected cost savings' (Mithas and Jones 2007).

Research that empirically tests the outcome predictions of game theory models would enable the refinement of existing theories (Mithas and Jones 2007) and its consequences (Hawkins, Randall, and Wittmann 2009). Further empirical research could help practitioners to design more effective selection processes and integrate those into their procurement strategies for improving firm performance (Mithas and Jones 2007). There is also a need to further experiment with the development and adaptation of auctions within the procurement process (Tassabehji 2010). Finally, empirical studies based on actual business applications of the two-phase supplier selection processes combining auctioning and bargaining are required to overcome some of the limitations of current studies based on simulation models and provide additional insights into procurement auction design (Tunca and $\mathrm{Wu} 2009$ ).

\section{Research methodology}

Action research forms the methodological basis for this study. The study was carried out in collaboration with a Spanish automotive group that supplies directly to OEM companies (PSA Group, Mercedes-Benz, Volvo) and Tier-1 corporations (Robert Bosch, TRW, ZF, Valeo). As part of their strategy to globalise their operations the case company agreed to establish a new manufacturing facility in Mexico in order to satisfy the demand from established customers in the North American Free Trade Agreement (NAFTA) region and engaged with the research team in the planning phase for this project. The researchers were involved in supporting the company in the design and execution of the supplier selection process for the construction of this new facility in Mexico. The company wanted an innovative approach to increase the competition between suppliers in a category that had no dominant supplier and ensure the best possible outcomes from the process. This provided an interesting case for the research 
team enabling to develop, structure and test new knowledge in relation to the application of game theory in this context.

Action research requires to enact change within the context of the study, which means that it was a particularly suitable method for this study. The choice of action also responds to calls for greater use of empirical research methods in this field of research (Hawkins, Randall, and Wittmann 2009; Mithas and Jones 2007). The aim was to generate new understanding of the application of game theory in the supplier selection process and at the same time to solve a specific practitioner challenge with the researchers being actively involved in the process of change (Eden and Huxham 1996; Coughlan and Coghlan 2002; Vignali and Zundel 2003).

Literature recognises that action research helps to embrace the 'complexity of buyer-supplier relationships, generating important theoretical insights and relevant managerial implications' (Maestrini et al. 2016). Game theory applied to supplier selection is still at the early stages of theory-building and therefore 'requires that the researcher is out in the field and in close contact with the environments being studied' (Handfield and Melnyk 1998). Additionally, in the field of applied game theory researchers have often used laboratories to study auction theory. This approach has considerable limitations since real world auction initiatives are significantly more complex and field studies are necessary to complement insights from laboratories (Mithas and Jones 2007).

When designing an action research project, it is important to develop a research framework that will guide the decisions during the study. This framework needs to incorporate elements to ensure the quality and reliability of the study, including a research frame that clearly defines the scope of the study and both the research and organisational objectives (Coghlan and Brannick, 2001), an action research process that 
identifies the data sources and data collection tools and ensures the implementation of the plan-take action-observe-evaluate action research cycle (Susman and Evered, 1978; Coughlan and Coghlan, 2002), and key operating principles such as the need to focus on the organisational context that surrounds the study and the creation of an action research steering committee to ensure close collaboration between the researchers and company stakeholders. Figure 1 shows the action research framework that was developed for this particular study.

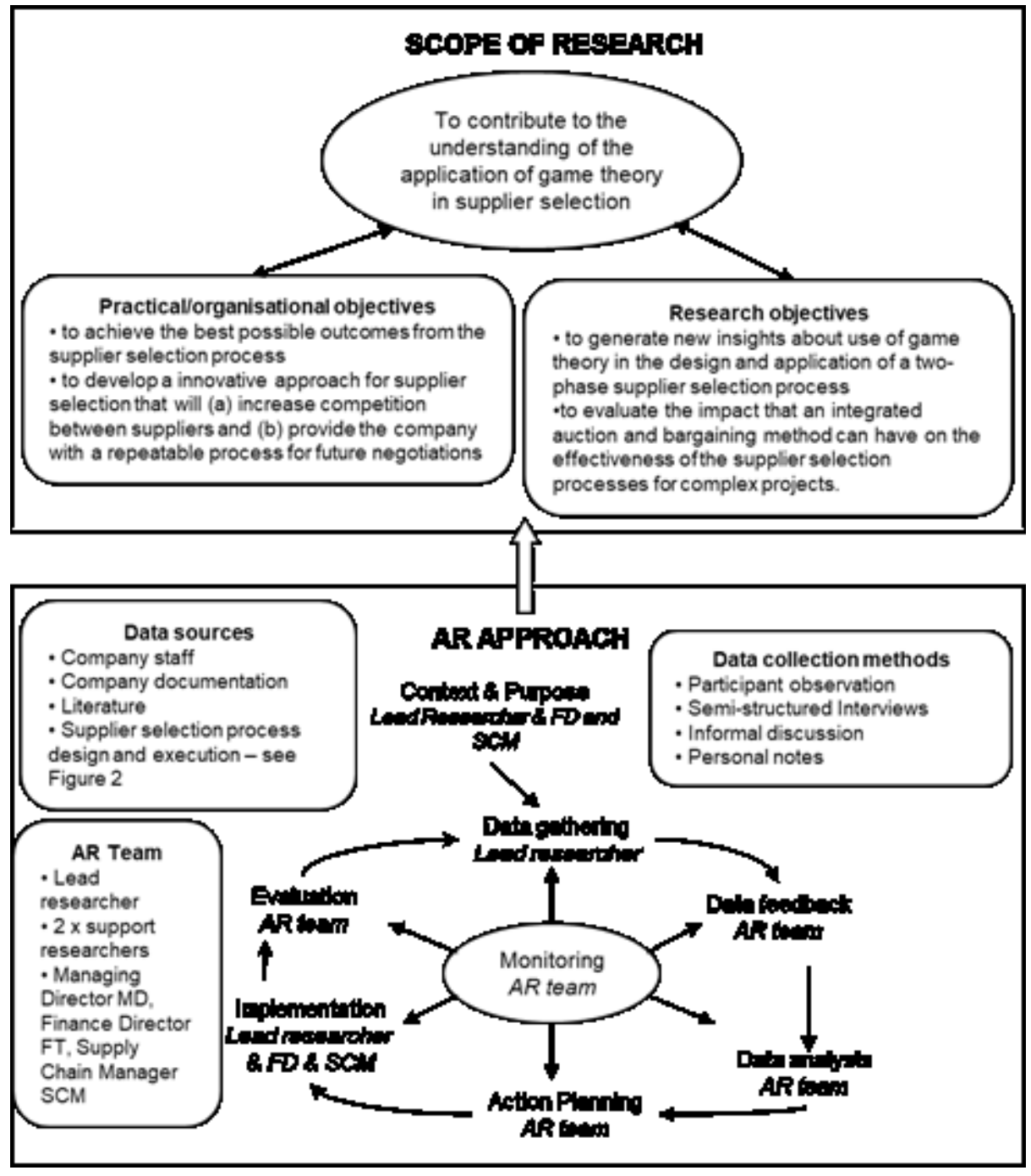

Figure 1. Action Research Framework

The research project was carried out over a 14-month period in 2014/15 with the main data collection phase lasting 4 months. At the end of the research project the new facility had been built and production had started. The data collection consisted of 
records from direct participation in project team meetings, semi-structured interviews with members of the senior management team, company internal documentation and direct observations from the entire design and execution of the supplier selection process.

The lead researcher led the design of the supplier selection process and played an advisory role during the onsite negotiations in Mexico. The rest of the research team gave specialised support on the design of the supplier selection process and provided a critical analysis of the process and findings in order to minimise potential bias and enhance the validity of the results.

The project team included senior managers from the case company including the Managing Director, Financial Director and Supply Chain Manager. This enabled the research team to continuously reflect and review the actions that were being taken throughout the process, which is a critical element to enhance the validity of action research studies. In addition, after completing the supplier selection process, several semi-structured interviews and group discussions with the management team were conducted. The project team that implemented the process in Mexico had also a separate session to reflect on the process and discuss the learnings from the novel experience.

\section{Field work: Applying game theory to the supplier selection process}

The action research study was conducted in four stages (Figure 2). The stages were designed using a qualitative approach rather than as a formal mathematical proposal, the latter being the case in many previous studies using game theory. The idea behind this was to promote the reader's intuition given that the concepts of game theory are not mathematical by nature (Osborne and Rubinstein 1994). The aim was to make the reader 
familiar with game theory concepts and possible decisions applied to purchasing processes, rather than to provide a mathematical justification.

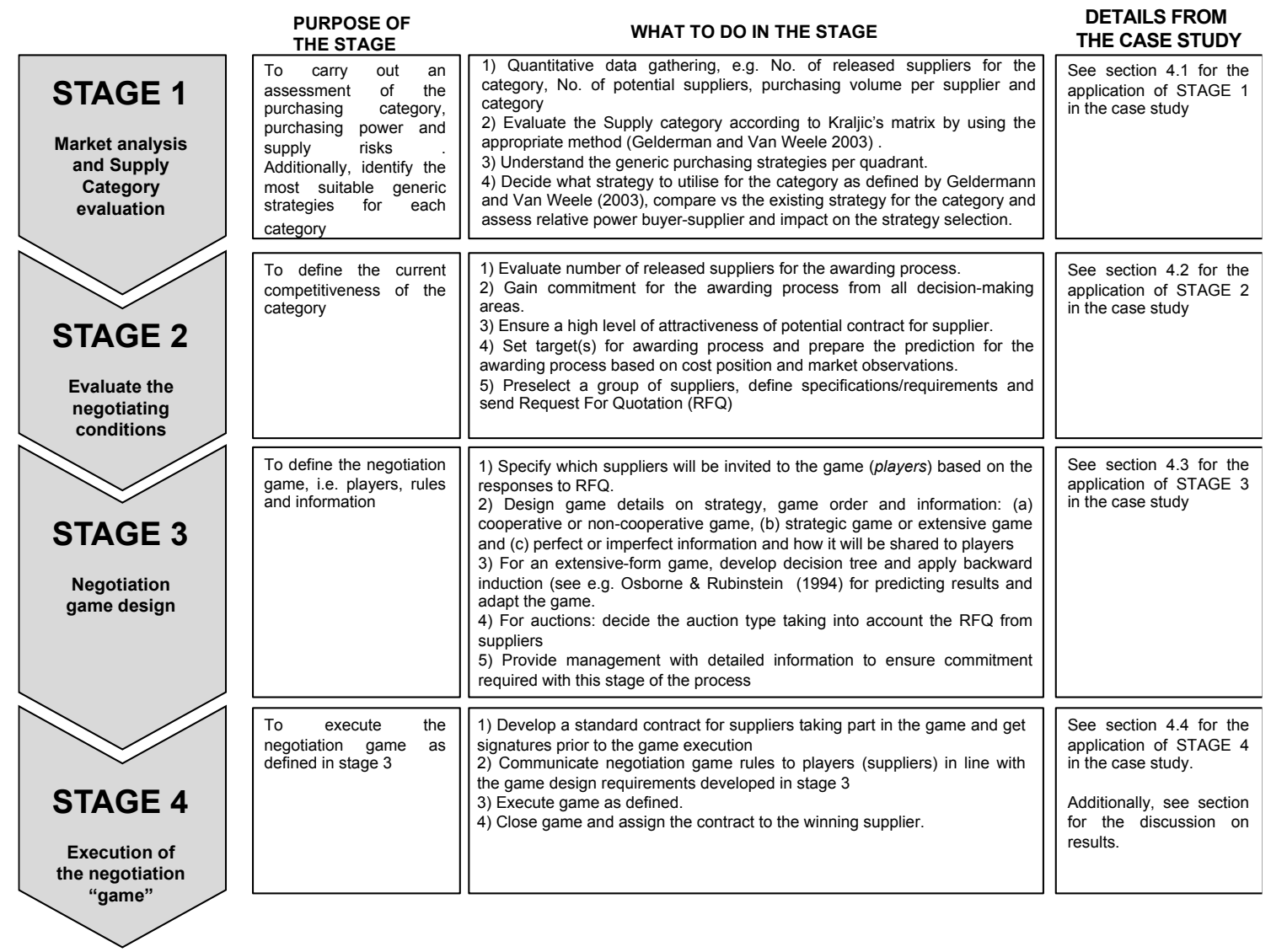

Figure 2. Process stages for designing a two-phase supplier negotiation process

From an organisational perspective, the aim was to achieve the best possible outcomes from the supplier selection process. To do this the research team systematically designed the supplier selection and negotiation strategies using the principles of game theory, which would enable some form of prediction of the potential outcomes and consequently would attract more competitive bids than when using the negotiation methods that the company had traditionally used (i.e. pure negotiation and without applying an approach based on concepts from game theory).

Stage 1 and 2 of the process were common to most supplier selection processes and not necessarily specific to game theory. For example, the activities included in stage 1 are often used in category management (Monczka, Handfield, Giunipero, \& Patterson, 
2008; Van Weele, 2009) and include specific approaches for the evaluation of the supply category and potential purchasing strategy for the category as defined by Gelderman \& Van Weele (2003). Similarly, stage 2 contained common steps and analysis widely used in supplier selection processes.

Stages 3 and 4 formed the main contribution to the supplier selection process and it is here where the key decisions to successfully apply features of game theory and execute the 'game' are described. Whilst there is a wide body of knowledge on strategic purchasing and supplier selection processes (in our case Stage 1 and 2) and also disparate literature on game theory on supplier selection processes (in our process Stage 3 and 4), there is limited research how they jointly affect firm performance (Kim, Suresh, and Kocabasoglu-Hillmer 2015; Pedraza-Acosta, Pilkington, and Barnes 2016). Hence, the integration of the strategic and tactical was deemed as critical for the success of this initiative.

Stage 3 (Negotiation 'game' design) was designed after careful consideration of the fundamental concepts of game theory when applied to auctions and extensive form games as defined in the literature review. Specific decisions in relation to the design of the negotiation strategy (e.g. decide what type of auction to use) were taken based on the particular needs of the company and nature of the project. In different situations and organisations contexts these choices would have probably been different. The aim of stage 4 (Execution of negotiation 'game') was to put game theory into practice by implementing the negotiation strategy and evaluating its impact on the organisation.

\subsection{Stage 1 - Market Analysis and Supply Category evaluation}

The first task was to conduct a detailed analysis of the Mexican construction sector specialized in mid-size industrial facilities. The team created an initial long list of potential suppliers based on recommendations from other companies and the Mexican 
and Spanish public economic development bodies.

The management team then evaluated the purchasing category using Kraljic's (1983) purchasing portfolio matrix (Figure 3) and the consensus method (Gelderman and Van Weele, 2003). Kraljic's matrix has become the standard in the field of category management and purchasing portfolio models (Gelderman and Van Weele 2005a; Monczka and others 2008; Tassabehji 2010) and it enables the definition of different purchasing strategies for each purchasing category . (Gelderman and Van Weele 2005b; Gelderman and Van Weele 2003; Gelderman and Van Weele 2005a). Such purchasing portfolio models have been also applied to construction sector and many other engineering-to-order (ETO) sectors (Ferreira, Arantes, and Kharlamov 2015; Ghanbarizadeh et al. 2019; Seth and Rastogi 2019). In fact, Seth and Rastogi (2019) considered that Kraljic can cope better than other multicriteria decision making methods with the engineering nature of items and cross-functional consideration required for the ETO context.

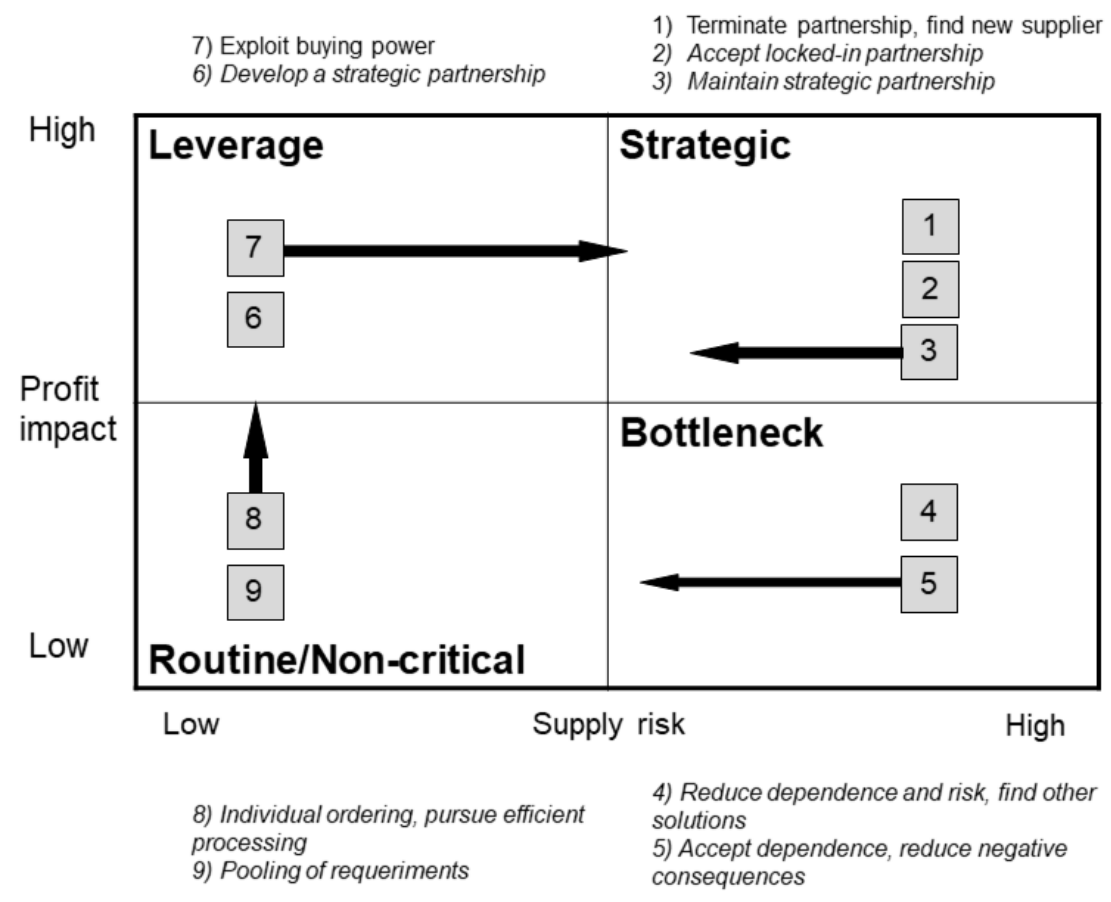

Figure 3. Kraljic's matrix and related purchasing strategies (Gelderman and Van Weele 2003) 
It is important for buyers to develop a clear understanding on how to implement Kraljic's matrix in specific negotiations, but nevertheless it remains still unclear how to translate Kraljic's logic into real-life negotiation contexts (Kang et al. 2018). Cox (2015) also concluded that 'Kraljic identified power positioning as a way of thinking about how to bargain and negotiate with suppliers, but he did not fully develop this insight $[\ldots]^{\prime}$ (p. 734). Nevertheless, some recent works have confirmed that certain negotiation styles fit better with particular items located (see Figure 3) in the 'Leverage', 'Strategic' and 'Bottleneck' quadrants (Kang et al. 2018; Aloini et al. 2019). Consequently, linking Kraljic matrix to the negotiation enables to complement and extend existing approaches and contribute to find the right focus for diverse negotiations (Kang et al. 2018).

In our research, the construction of the new plant was positioned in the 'Leverage' quadrant (Figure 3) by the case company, given that (1) this would be one of the highest investments carried out by company and (2) it was defined as having low supply risk due to the high number of qualified and reliable suppliers. The position in the matrix suggested two possible optimal strategies to adopt, either 'Exploit buying power' or 'Develop a strategic partnership' (Gelderman and Van Weele 2003). Nevertheless, the literature discussing 'Leverage' items has usually recommended aggressive approaches to exploit the full purchasing power and having short to medium term contracts (Caniëls and Gelderman 2007). Also, the experimental test done by Kang et al. (2018) found that most part of the practitioners prioritise the competitive negotiation to obtain the maximum effect of price reduction for leverage items.

In our case, researchers developed individual semi-structured interviews and group discussions to decide whether to promote a turnkey project with a close partnership (closer to 'Develop a strategic partnership) or to support a highly 
competitive bidding (Exploit buying power) via the application of game theory. The latter was chosen as the preferred option because the company needed to achieve major cost reductions in every investment in order to boost the ambitious strategic growth plan to double turnover in 6 years.

\subsection{Stage 2 (Evaluate the negotiating conditions)}

The Managing Director and Finance Director set the targets for the project during the initial interviews with the research team. The research team had access to primary data for construction project costs in Mexico with similar characteristics. This data was used to support the analysis of the potential outcomes from the awarding process and also to evaluate the competitiveness of the quotes received from suppliers. The case company hired a local architect firm to develop the architectural specifications that would be used as the technical standard during the awarding process.

The team invited the listed suppliers to send the relevant information via a standard Request For Information (RFI). From the list of suppliers that responded to the RFI, and based on the information they submitted, nine candidates were preselected. All the suppliers were Mexican companies except one subsidiary of a Spanish construction company.

The research team and the project manager from the case company coordinated a working group to set the required specifications for the new industrial facility. These specifications were the basis for the Request For Quotation (RFQ). Detailing the project requirements and specifications was critical in the development of a supplier selection process based on game theory given that all rules of the game had to be specified up front and there was no room for changes once the process started. This is in line with previous research 
RW.ERRORRW.ERROR(Caniëls and van Raaij 2009; Hawkins, Gravier, and Wittmann 2010; Hanák and Šelih 2017; RW.ERROR - Unable to find reference:doc:5ddf154de4b0e775cfc5efae; Fugger, Katok, and Wambach 2019; Schoenherr 2019) that argues that applying reverse auctions can be challenging in comparison to other traditional procurement methods if the specifications are not explicitly detailed in advance. Hanák and Šelih (2017) added that 'in the case of construction works, this requires, above all, the preparation of high-quality project documentation'.

The case company met with the management team of each of the nine preselected suppliers to present the technical details of the project and discuss the contract awarding process. Suppliers were asked to respond to the RFQ based on the technical requirements and additional non-price evaluation factors (e.g. project delivery timescales, previous experience in similar projects, financial position, technical and staff capabilities, fulfilment of submission deadline). These non-price evaluation factors were applied during the initial shortlisting, which led to the selection of the suppliers that would go through to the auctioning stage. Throughout the initial part of the process the case company made sure that the information shared with all suppliers was consistent in order to avoid information asymmetry, a key requirement for applying game theory.

The case company received four 'in full and on time' offers from suppliers A, G, $\mathrm{H}$ and $\mathrm{L}$ (see figure 4). The rest of the suppliers were eliminated from the process. The evaluation of the four offers was rooted on a TCO approach. As a result, the lowest offer was from Supplier G and this was used as the comparative benchmark (i.e. RFQ for Supplier $G=1$ ) for the study. This offer was also the so called 'reserve price' or the highest price that the case company was willing to pay for the new facility. 


\begin{tabular}{|c|c|c|c|c|c|c|}
\hline \multicolumn{2}{|r|}{ Project summary } & \multicolumn{2}{|c|}{ Supplier G } & Supplier L & Supplier $\mathbf{H}$ & Supplier A \\
\hline & Construction of new industrial facility in Mexico - Automotive soctor & & EUR & EUR & EUR & EUR \\
\hline & Construction work - summary of main items & $\begin{array}{l}\text { Average \% vs. } \\
\text { Total cost }\end{array}$ & & & & \\
\hline 1 & Construction preliminaries & $4,7 \%$ & $3,9 \%$ & $2,6 \%$ & $7,5 \%$ & $4,2 \%$ \\
\hline II & Construction of the main building: structure, floor and closing & $28,4 \%$ & $27,3 \%$ & $27,5 \%$ & $31,1 \%$ & $27,0 \%$ \\
\hline IIII & $\begin{array}{l}\text { Electrical Instalations, Hidraulic and pneumatic instalations, Fire } \\
\text { protection, Water supply }\end{array}$ & $26,7 \%$ & $28,5 \%$ & $30,9 \%$ & $21,3 \%$ & $27,3 \%$ \\
\hline IV & Logistics platforms & & $0,0 \%$ & $0,0 \%$ & $0,0 \%$ & $0,0 \%$ \\
\hline & Inbound logistics platform & $1,5 \%$ & $1,5 \%$ & $1,4 \%$ & $1,3 \%$ & $1,8 \%$ \\
\hline & Finished product logistics platform & $2,9 \%$ & $2,6 \%$ & $3,1 \%$ & $2,9 \%$ & $3,2 \%$ \\
\hline $\mathrm{v}$ & Construction of the outter area & & $0,0 \%$ & $0,0 \%$ & $0,0 \%$ & $0,0 \%$ \\
\hline & Maneuver yard & $2,5 \%$ & $2,8 \%$ & $2,3 \%$ & $2,7 \%$ & $2,4 \%$ \\
\hline & Outter asphalt & $6,8 \%$ & $7,0 \%$ & $7,4 \%$ & $6,3 \%$ & $6,6 \%$ \\
\hline & Main access, security perimeter and parking lot & $5,7 \%$ & $6,1 \%$ & $5,6 \%$ & $5,5 \%$ & $5,6 \%$ \\
\hline $\mathrm{VI}$ & Building for Security services, Video-survaillance & $1,8 \%$ & $1,6 \%$ & $1,8 \%$ & $1,3 \%$ & $2,4 \%$ \\
\hline VII & Machine room (transformator and other machines) & $1,1 \%$ & $1,0 \%$ & $0,9 \%$ & $1,3 \%$ & $1,1 \%$ \\
\hline VIIII & Production offices (inside factory) & $1,2 \%$ & $1,1 \%$ & $1,0 \%$ & $1,4 \%$ & $1,2 \%$ \\
\hline $\mathrm{IX}$ & Office building, dressing room, Bathrooms & $15,1 \%$ & $14,9 \%$ & $13,8 \%$ & $16,0 \%$ & $15,7 \%$ \\
\hline $\mathrm{x}$ & Special foundation for cold forging machines & $1,0 \%$ & $1,2 \%$ & $1,1 \%$ & $0,8 \%$ & $1,1 \%$ \\
\hline $\mathrm{XI}$ & Garden and outter decoration & $0,5 \%$ & $0,5 \%$ & $0,6 \%$ & $0,4 \%$ & $0,4 \%$ \\
\hline & RFQ offer (before two-phase supplier selection) & & 1,00 & 1,06 & 1,25 & 1,08 \\
\hline
\end{tabular}

Figure 4. Summarized view of offers from four qualified suppliers and the percentage of cost per project item

The figure 4 shows the percentage of the total cost that each of the main items that compose the technical project breakdown. This includes the most complex aspects of the construction (e.g. construction of the main building, office building or electrical installations) and other more standard elements of the construction (e.g. Production offices, logistics platforms, outer decoration). The technical complexity of the project mainly laid on the design and construction of the main building. On the one hand, the building had to be prepared for a posterior expansion (three expansion phases that would enable a four times bigger industrial surface), which also influenced the electrical, hydraulic and pneumatic installations. On the other hand, the case company have extremely differentiated needs for the industrial usage of machines: for example, the same floor had to admit cold forging machines (for up to $45 \mathrm{~mm}$ diameters of wire rod) and the very sensible automatic control machines (artificial vision technology).

These differentiated process technologies had a big impact on the functional requirements for e.g. the main building regarding floor resistance, avoidance of vibrations, etc. 


\subsection{Stage 3 (negotiation game design)}

The research team designed the awarding process ('game') taking into consideration the number of qualified suppliers, their offers to the RFQ, the relative cost position among the (four) qualified suppliers, the research team's assumptions regarding the suppliers' power and market situation, and the technical aspects and complexity of the purchased 'good' (in this case, the construction of the new facility). The following rules were designed for the awarding process:

(1) Non-cooperative game: only one supplier to be awarded with the final contract.

(2) Two-phase game design: The first phase to be conducted using a modified Japanese auction. The second phase to be based on a negotiation process with the suppliers that qualify from the first phase. An 'accept or reject' approach ('take it or leave it') to be used in this second phase with the best supplier from the previous phase given first priority in the negotiations, followed by the suppliers in the order that were ranked during the previous phase.

(3) All 'players' (suppliers) to be provided with imperfect information: none of the players have access to complete information about the game, e.g. the number of suppliers, bids from other suppliers or relative position versus other suppliers.

Rules (1) and (3) were based on the fact that the case company had a clear focus on maximising competition during the awarding process, exploiting the purchasing power and getting the highest cost reduction possible. These decisions were made comparing and contrasting suggestions from previous literature (Osborne and Rubinstein 1994; Dixit and Skeath 1999) with the specific contextual characteristics of the case company. 
Rule (2) is the most noteworthy in terms of the application of game theory in a real awarding process. The research team agreed to design a two-phase awarding process due to the level of complexity and uncertainty of the project and the need to take a multi-attribute approach for evaluation (i.e. combining price with other factors). This decision aligns with relevant research in this area (Pham et al. 2015).

The aim of the first phase was to incentivise suppliers to compete aggressively and reduce their offers in order to get a priority rank for the second phase, which could potentially mean being the first supplier to receive a contract offer. The research team decided to develop a modified version of the Japanese reverse auction to structure this first phase. During a pure Japanese reverse auction, the offeror reduces the price in each bid (in practical terms it is the buyer who communicates the updated bids to the suppliers) and after every bid each supplier signals their willingness to continue in the auction at the current price, until only one supplier is remaining. The Japanese reverse auction can sometimes lead to the same results as Vickrey's 'second-price sealed bid auctions' (Vickrey 1961), which is based on 'truthful bidding' by suppliers. This means that suppliers would bid based on their real cost level and minimum margin that are willing to get from that project. Vickrey's auctions also lead to bidders not being influenced by the number of other bidders, the bidder's assumptions on others' costs or the bidder's assumptions on others' assumptions in regards to cost. Japanese RA and Vickrey's auction are second price auctions (see table 1), which means that the second best 'indifference price' (the threshold between a 'good' or 'bad' deal for the supplier based on the cost level and the minimum margin) will be final price. That is not always the most efficient result from a financial perspective since the auction winner may have a much lower indifference price that would not be considered. A key difference between pure Japanese and Vickrey's auctions is that there is information available to 
players during Japanese auctions that is never available during Vickrey's (sealed bid) auctions. Therefore, an important weakness in Japanese auctions is that bidders know when rivals drop out and therefore players can incorporate this information to their decisions. As a result, these two types of auctions 'can easily lead to different outcomes in the practice' (Steiglitz 2007). Taking into account the above limitations, the research team designed a modified Japanese reverse auction with the following parameters:

- No visibility to the bidder regarding how many bidders remain in each round, in order to reflect Vickrey's truthful bidding.

- Auction to keep running until the last bidder decides to abandon the auction, rather than when there is one remaining bidder. This can have a significant impact because it forces the last supplier to bid truthfully based on their indifference price.

- Other auction dimensions: setting a soft-close (no time limit for the auction), a starting price by the case company, a reserve price (the lowest offer from the responses to the RFQ) or the case company deciding on the price reduction between bids.

This modified Japanese reverse auction was designed to force a bidder to stop signaling the willingness to remain at the point when the bid reaches their 'indifference price'. This assumes that suppliers have a dominant ${ }^{1}$ strategy (that is to have a truthful bidding) and that the auction winner will be the one with the best indifference price instead of the second price as proposed by the Japanese and Vickrey's models.

The second phase of the bidding was designed as an extensive game, where the bidder would be offered the award of the contract and could either accept or reject it. If

\footnotetext{
${ }^{1}$ The qualified term is 'weakly dominant' but we will skip this theoretical detail.
} 
the bidder accepted the offer they would be awarded with the contract; if not, the next bidder would be given the same chance to get the contract. This form of extensive game is also known as 'take-it-or-leave-it'(TIOLI) and is a form of the ultimatum game, which is a bilateral price negotiation and has been extensively discussed by renowned game theory authors (Binmore, Rubinstein, and Wolinsky 1986; Reny 1993; Gale, Binmore, and Samuelson 1995). These games are always focused on how to close the gap between the buyer's and bidder's indifference prices.

Extensive games are part of bargaining methods in game theory and are different to a typical buyer-supplier negotiation in that there is a predefined sequential structure to the decision making process and a set of predictions in relation to the possible decisions made by the players and outcomes from the game. In this case, the team modelled the extensive game through the use of decision trees and a backward induction approach, allowing the case company to have a detailed set of predictions to support the decision making process during the supplier negotiations. In addition, the awarding rules are predefined and known by the buyer and the suppliers before the start. Making the process transparent and highlighting the incentives leads to increased competition amongst suppliers. In the particular case of TIOLI ultimatum games Berz (2014) stated that 'the line between a hard TIOLI and a more or less final offer negotiation is fuzzy. You can only achieve really great results with TIOLI if you have established a credible reputation of no longer negotiating after a TIOLI has been rejected. Of course, the competition argument helps this. If you counterpart knows that you have an alternative, the credibility of a hard TIOLI increases'. For the case company presented in this paper, this meant that there was a clear commitment to adhere to the rules defined by the research team and to accept the results from the 
TIOLI process without any additional post-bargaining negotiations that could harm the credibility of the TIOLI process.

The contract price, payment terms and minor technical modifications to the specifications (the latter only if proposed by the case company and accepted by the architect firm) were conditions that could be reviewed during this extensive game. The research team calculated the financial impact of these potential changes in case they were considered during the negotiation phase. There would be no changes to the project timeline and major technical specifications allowed during this phase. All these conditions were defined at the start of the awarding process and communicated to the suppliers.

\subsection{Stage 4 (game execution)}

The supplier selection process was held with the participation of case company's Purchasing Director and the Supply Chain Director, as well as the lead researcher. The day before the awarding process, the case company arranged individual on-site meetings with the four qualified suppliers. The research team explained the characteristics of the two-phase awarding process to each of the suppliers and clearly stated that the established process and timeline would be the only route to negotiate. The case company rented five offices on a business centre, one for each of the four suppliers and one for the research team. These offices were in separate corners of the business centre to avoid any contact or information sharing between the suppliers. Suppliers entered the business centre at different times and through different entrances in order to ensure that they received no additional information in relation to the number and identity of other suppliers.

Figure 4 shows the final bids for each supplier and Figure 5 illustrates the evolution of the auction and negotiation process. The first phase (modified Japanese 
reverse auction) lasted 20 bidding rounds, which took nearly four hours. This phase finished when the last remaining supplier (supplier G) abandoned. Outcomes from the auction were:

- Supplier A abandoned the auction even before starting (with an offer of 1.12).

- Supplier H lasted two bidding rounds and abandoned with an offer of 1.03 (RFQ offer was 1.25).

- Supplier L also abandoned the auction after the second bidding round with an offer of 1.03 (RFQ offer was 1.06). However, on round 8, this same supplier came to the case company offering a price of 0.89 . That price level was lower that the auction's best price up until that point (0.93) and led to a discussion between the case company and lead researcher as to whether they should accept it. The case company did not accept the offer to ensure they adhered to the rules set for the awarding process so supplier L remained with their best auction bid of 1.03. However, 0.89 was considered as a valid offer in case supplier L qualified for the second phase.

- Supplier G played alone in the auction from the third to the $20^{\text {th }}$ round and finished with a best bid of 0.83 (RFQ offer of 1). Note that if a pure Japanese auction had been applied, then the supplier $G$ would have won the auction by bidding 1.02 (a significantly higher price that the final result).

- Only two suppliers were invited to the 2nd negotiation stage: Supplier G and L.

The second phase was designed as a TIOLI game (see results in figures 5 and 6). The case company met supplier $G$ and proposed a last offer, which if accepted would result in the contract been awarded to them. If supplier G did not accept this offer, a 
'take-it-or-leave-it' offer would be presented to supplier L. The following were the criteria set for this second phase:

- Supplier G would be offered $0.75(+0.02$ on variable payment depending on fulfilling the planned construction time)

- If supplier $\mathrm{G}$ rejected that final offer, supplier $\mathrm{L}$ would receive a final offer of 0.8 (a price in between the previous offer and Supplier G's lowest bid in the previous phase).

- If supplier L rejected that final offer, supplier G would be awarded the contract with a final offer of 0.83 (the last bid from the first phase of the process and therefore a kind of reserve price).

This second phase was relatively fast as supplier $\mathrm{G}$ accepted the offer of 0.75 from the case company and signed the legally binding contract. Supplier L tried to make an offer during this second phase (during the time when Supplier G was assessing the offer received) but the case company did not accept the offer given that this was not within the rules of the game.

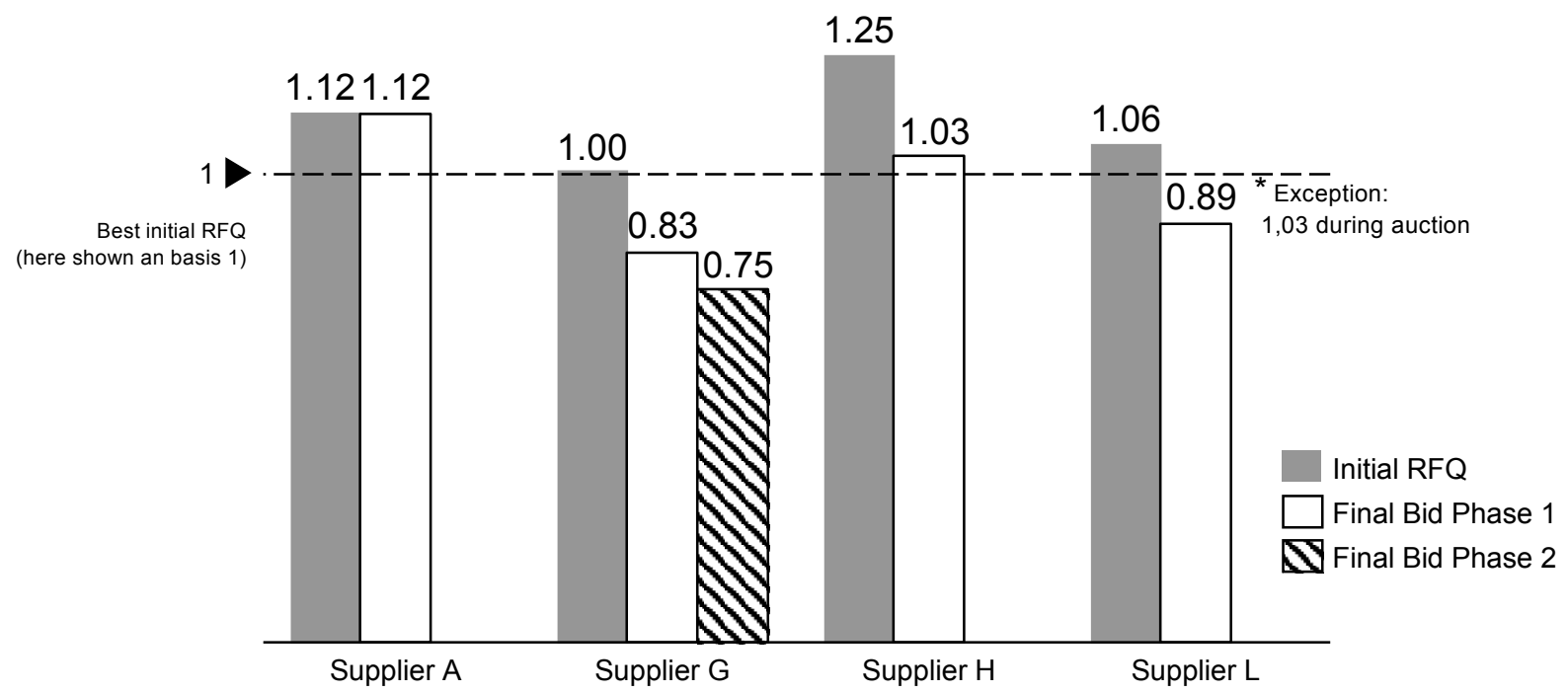

Figure 5: Best supplier offers at initial RFQ and after two phases of the negotiation 


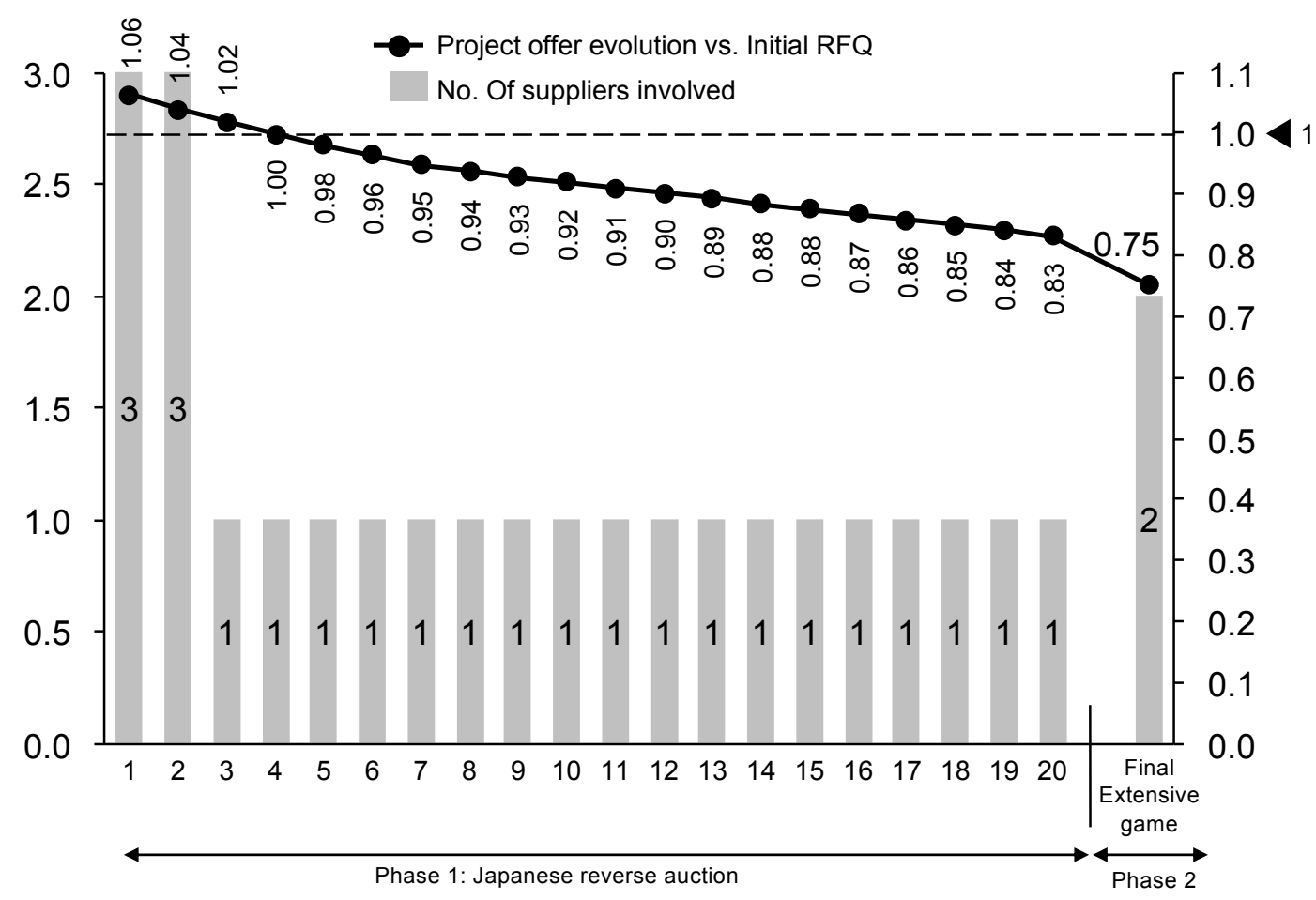

Figure 6: Price evolution during auction and extensive game (stage 4 of the framework)

\section{Discussion and evaluation}

This study was carried out with careful consideration of the criteria for evaluating the quality of action research. These include theoretical novelty, applicability of the findings in other situations, rigour of enquiry, practical relevance and usefulness (Kasanen, Lukka, and Siitonen 1993; Eden and Huxham 1996; Coughlan and Coghlan 2002). These criteria respond to previous criticism of action research as 'consulting masquerading as research' (Coughlan and Coghlan 2002) and the lack of repeatability and generalisability due to the need to solve a specific problem in a particular context.

\subsection{Theoretical implications}

The novelty of this research stems from the application of game theory to design and implement a two-phase supplier selection process combining auction and bargaining methods and evaluating its impact in the context of selecting a supplier for a 
construction project. The literature review showed that knowledge on the actual design characteristics and application of game theory principles in supplier selection was limited even when the benefits of applying game theory have been previously discussed (Wagner and Schwab 2004). The key contributions of the study are twofold. First, this study presents a unique case combining auctions and bargaining for supplier selection, which has limited exposure in current literature (Huh and Park 2010). In doing so it demonstrates the impact that such an approach can have in increasing the effectiveness of the supplier selection process. In practice, many organisations will often go through a negotiation phase following an auction, especially when managing complex projects. However, there is no evidence of studies where this bargaining phase was designed using the principles of game theory.

This paper presents a novel two-phase approach that includes a structured and deliberate bargaining phase designed around game theory principles. By using these principles and combining auction and bargaining methods the case study company achieved better outcomes that originally planned. This work supports the proposal of Tunca and $\mathrm{Wu}(2009)$ regarding the potential of two-phase (supplier selection) processes and provides a unique case of application in a real organisational context, with previous empirical research limited to simulations models. Empirically testing the outcomes of the application of game theory models is rare within the supplier selection literature and these findings enable refining existing theory and developing a better understanding of its consequences (Mithas and Jones, 2007; Hawkins, Randall, and Wittmann 2009 Tassabehji, 2010). Second, this study responds to calls for further research and analytical prediction into the application of reverse auctions for complex and highly customised items (Aital, Pawar, and Behl 2017; Hanák and Šelih 2017; Schoenherr 2019; Fugger, Katok, and Wambach 2019). 
An important feature of the process presented in this paper was the development of a modified Japanese reverse auction, combining the features of the pure Japanese and Vickrey's auction models. This modified reverse auction model enabled overcoming their respective weaknesses in addressing the particular requirements for supplier selection in complex projects. As a result, this study extends the knowledge on how principles of game theory can be applied to enhance the outcomes of the supplier selection process in complex project environments. The study provides a detailed description and justification of the characteristics and parameters ${ }^{2}$ chosen to design the supplier selection process, which up until now was largely omitted from the literature (Mithas and Jones 2007; Wyld 2011). By doing so, the study also contributes to better understanding the reasons why game theory can have a positive impact on the overall process.

Also, our particular case has provided interesting insights around the usage of purchasing portfolio models (e.g. Kraljic's Matrix) in negotiations. For example, by having utilised Kraljic's matrix prior to the two-phase negotiation has enabled to support the proposal by Karabağ and Tan (2018) in relation to the influence of product category on the design of reverse auctions, pricing strategy and buyer surplus. Also, our case supports the findings of Kang et al (2018) regarding the best fitting negotiation style for 'Leverage' items. Also, we have shown evidences regarding the importance of integrating the strategic and tactical purchasing levels that has been argued in previous research (Kim et al., 2015).

\footnotetext{
${ }^{2}$ In this particular case the key parameters of the game were non-cooperative, two-phases (modified Japanese auction followed by extensive game) and imperfect information.
} 
When discussing the generalisability of the findings it is important to remember that action research is specific to the context of action and does not aim to create universal knowledge (Coughlan and Coghlan 2002) even if it is important to understand the implications of the findings in other contexts (Eden and Huxham 1996; Coughlan and Coghlan 2002; Coghlan and Brannick 2014). We could argue that the four-stage process presented in this paper would be applicable within other organisations, especially after careful consideration of the particular purchasing category (Kraljic, 1983) and the best fitting negotiation style according to the positioning of the category (Kang et al. 2018). The specific design parameters and characteristics would clearly be influenced by the organisational context and the specific nature of each supplier selection process.

In order to enhance the research rigour and validity of the study the research team ensured that guidelines for action research were carefully adopted (Coughlan and Coghlan, 2002). This included documenting a detailed research process, creating a research team involving key stakeholders, continuously deploying the plan-act-observereflect cycle of action research and regularly testing the assumptions for public scrutiny with key stakeholders from the case company. The research team structured the data throughout the design and implementation stages of the study and the data from the interviews and observations was clearly documented to enable reflective discussions with the company.

\subsection{Managerial implications}

The applied nature of action research requires the research to demonstrate the practical relevance and usefulness of the outcomes in an organisational context (Susman and Evered 1978; Kasanen, Lukka, and Siitonen 1993; Eden and Huxham 1996; Coughlan and Coghlan 2002). In the case of this study the aim for the company 
was to maximise the competition between suppliers in order to achieve the best possible outcomes from the supplier selection process.

Based on a detailed analysis of the original proposals submitted by suppliers and the primary data from other construction projects of similar characteristics, the research team concluded that a price of around 0.9 would be considered satisfactory when using a traditional negotiation strategy (i.e. not based on game theory). Based on the same data sources, the researchers forecasted a price of 0.82 as a likely outcome from the auctioning phase, which was close to the 0.83 price that resulted from the first phase (auction) of the process (Figure 5). The final price (0.75) was negotiated during the second phase and this included some minor changes to the technical specifications and financial terms. Logically these changes affected the basis for the predictions and arguably the validity to compare the results from negotiation stage one and two (due to changes to the project scope). However, the financial impact of these minor changes had been assessed by the case company beforehand and were valued at $0.035(0.025$ for the technical changes related to reduction in quality specifications for selected parts and 0.01 for shorter payment terms to the construction company). As a result, the research team used 0.785 (final price of $0.75+$ value of changes at 0.035 ) as the basis for comparison with the outcomes of stage $3(0.83)$, resulting in a price reduction of 0.045 points.

Price alone is rarely an accurate indicator of success in complex projects, with construction projects being often cited for significant deviations on budget, quality and timeliness after the contract has been awarded. Additionally, with the aim of driving down prices, auctions can incentivise suppliers to identify areas for reducing costs (often leading to reduction in quality) and to find ways in which to increase scope changes and revenue sources post award, which is generally a more favourable context 
to negotiate for the supplier (Council 2005). Taking into consideration the criticisms of auctioning methods for complex projects the research team implemented a carefully designed process that addressed these challenges. Results show that the project met all agreed requirements and the facility was completed on time, on budget and on quality. Also, the ex-post TCO calculation did not show major differences versus the ex-ante TCO calculation executed during the evaluation of offers (stage 2). These results provide empirical evidence to demonstrate that a combined auction and bargaining approach can overcome the limitations previously addressed in the literature and enhance the bargaining power of the buyer in negotiations for complex projects, therefore supporting the arguments by Tunca and Wu (2009) and Huh and Park (2010). The senior management team had initially some doubts about the practical nature of applying game theory. However, their reaction to the outcomes of the process was highly satisfactory as a result of achieving a competitive contract following a transparent and fully traceable design process. The price achieved exceeded their most optimistic expectations with the Purchasing Director commenting that 'our internal target through a normal and aggressive negotiation would have never been lower than 0.95. If at all 0.90. But we are at 0.75 , unbelievable.' In regards to the approach developed for the supplier selection process the CFO commented that 'game-theory works.... I thought it would last two or three rounds... It is amazing to see how we could predict with that precision what would happen here.... I can now trace why we made each decision and I will continue doing it that way.' Interestingly staff highlighted the fact that the actual negotiation phase was relatively straightforward given that most of the work had been done at the planning stage. The Supply Chain Director stated that this was 'the negotiation with the lowest effort I have had in more than 20 years of career in the automotive industry'. At the same time, everyone was in agreement about 
the fact that applying game theory requires expert knowledge and a significant time investment during the preparation phase prior to the negotiation and it is only worth doing it if there are enough savings to achieve or a difficult supplier relationship to manage. Following this positive experience, the research team was invited to design and execute a similar supplier selection process for the construction of a new facility in Europe during 2017.

Regarding the practical implications beyond the context of the specific case study presented in this paper, the findings from our research can support purchasing practitioners in identifying critical design elements to enhance the effectiveness of their supplier selection processes. Previous literature highlighted the need to enhance empirical evidence of the adoption and adaptation of auction theory for purchasing processes (Tassabehji 2010) and this study contributes to developing a better understanding of the design of an integrated (auction and bargaining) process and the impact in the context of complex projects. Detailing how to develop and implement a two-phase model for supplier selection and discussing the reasons for choosing the specific game design parameters can provide a better understanding of the application of game theory, without the need to necessarily understand the theoretical underpinnings.

\section{Conclusions}

Supplier selection is a critical process enabling the supply management function to act as a strategic contributor to the firm. At the same time is considered to be a potential source of difficult and complex decision-making challenges for practitioners. Literature discussing the application of game theory to supplier selection processes is limited and lacking on empirical evidence, particularly when applied to complex projects and highly customised items. This study contributes to closing this knowledge 
gap and shows that a two-phase approach can support more intense competition between suppliers and enhance the effectiveness of the supplier selection process also in complex projects. The integration of auction and bargaining methods and the evaluation of their impact is particularly relevant given the limited exposure in current literature.

The nature of the action research study provided an in-depth picture of the application of game theory, supporting the view from Van Weele and Raaij (2014) regarding the relevance of this field of research to develop superior bargaining power over suppliers. The ability to better predict the possible decisions and outcomes from a negotiation can be a powerful mechanism to support purchasing practitioners in their continuous search for more effective and efficient supplier management processes.

\subsection{Limitations and future}

This study is limited to a single case company. Each stage of the framework presented in this paper was developed with the generalisability of the framework in mind and therefore the research team is confident of its application in other negotiations, auctions and sectors. However, carrying out further empirical studies across different sectors and product categories would significantly increase the validity of the approaches presented here.

Our case included a negotiation that was designed to maximise competition among suppliers. This design responded to a conscious decision met by the case company by using our systematic process to apply game-theory to supplier selection processes of complex items. Therefore, that leads to two limitations: the fact of using Kraljic's matrix as purchasing portfolio model and the competitive nature of negotiation itself. Therefore, additional negotiations that enable to discuss items on other Kraljic's quadrant may provide cases with other nature of negotiation, for example based on the 
observations from Kang et al. (2018): cooperation for 'strategic' items or accommodation for 'bottleneck' items.

Also, to study a real-world competitive negotiation by means of action research could provide very valuable insight to the controversial aspect of how mutual buyerseller trust or the sense of opportunism is affected by such negotiations (e.g. auctions)."

Further studies of the modified Japanese reverse auction would help in providing additional insights to refine the design assumptions. This modified form of the Japanese reverse auction could be of great interest for practitioners, given that it is relatively easy to apply and needs no complex auction infrastructure. Finally, the aim of this study was to provide a more intuitive model for purchasing management academics and practitioners and it intentionally avoided taking a more mathematical approach to the application of game theory. Models based on a more analytical approach would be interesting to complement this work.

Finally, our modified Japanese reverse auction has taken into consideration aspects of the 'indifference price' of offeror to optimize the auction results. According to auction theory the 'indifference price' includes an 'strategic margin' that is dependent on the company's risk aversion and assessment of the competition. Further research analyzing the risk aversion decision on practical case studies from the industry would provide enriching perspectives to confront with the existing theoretical assumptions. 


\section{Bibliography}

Aital, Padmanabha, Prashant V. Pawar, and Abhishek Behl. "Systematic Literature Review on Electronic Reverse Auction: Issues and Research Discussion." International Journal of Procurement Management 10, no. 3 (2017): 290-310. doi:10.1504/IJPM.2017.10003366.

Alard, Robert, Philipp Bremen, Josef Oehmen, and Christian Schneider. "Total Cost of Ownership Considerations in Global Sourcing Processes." In Advances in Production Management Systems. New Challenges, New Approaches. Vol. 338, 491-498. Berlin, Heidelberg: Springer, 2009.

Aloini, Davide, Riccardo Dulmin, Valeria Mininno, and Pierluigi Zerbino. "Leveraging Procurement-Related Knowledge through a Fuzzy-Based DSS: A Refinement of Purchasing Portfolio Models." Journal of Knowledge Management 23, no. 6 (2019): 1077-1104. doi:10.1108/JKM-10-2018-0614.

Anandalingam, G., Robert W. Day, and S. Raghavan. "The Landscape of Electronic Market Design." Management Science 51, no. 3 (2005): 316-327. doi:10.1287/mnsc. 1040.0345 .

Bartezzaghi, E. and S. Ronchi. "E-Sourcing in a Buyer-Operator-Seller Perspective: Benefits and Criticalities." Production Planning \& Control 16, no. 4 (2005): 405412.

Berz, Gregor. Game Theory Bargaining and Auction Strategies: Practical Examples from Internet Auctions to Investment Banking. Second Edition ed. London: Palgrave Macmillan, 2014.

Binmore, Ken, Ariel Rubinstein, and Asher Wolinsky. "The Nash Bargaining Solution in Economic Modelling." The Rand Journal of Economics 17, no. 2 (1986): 176188. doi:10.2307/2555382.

Börgers, Tilman. An Introduction to the Theory of Mechanism Design. Oxford: Oxford University Press, 2015.

Brandon-Jones, Alistair and Katri Kauppi. "Examining the Antecedents of the Technology Acceptance Model within E-Procurement." International Journal of Operations \& Production Management 38, no. 1 (2018): 22-42. doi:10.1108/IJOPM-06-2015-0346.

Caniëls, Marjolein C. J. and Cees J. Gelderman. "Power and Interdependence in Buyer Supplier Relationships: A Purchasing Portfolio Approach." Industrial Marketing Management 36, no. 2 (2007): 219-229. doi:10.1016/j.indmarman.2005.08.012.

Caniëls, Marjolein C. J. and Erik M. van Raaij. "Do all Suppliers Dislike Electronic Reverse Auctions?" Journal of Purchasing and Supply Management 15, no. 1 (2009): 12-23. doi:10.1016/j.pursup.2008.10.003. 
Carter, Craig R. and Cynthia Kay Stevens. "Electronic Reverse Auction Configuration and its Impact on Buyer Price and Supplier Perceptions of Opportunism: A Laboratory Experiment." Journal of Operations Management 25, no. 5 (2007): 1035-1054. doi:10.1016/j.jom.2006.10.005.

Chaturvedi, Aadhaar, Damian R. Beil, and Victor Martínez-de-Albéniz. "Split-Award Auctions for Supplier Retention." Management Science 60, no. 7 (2014): 17191737.

Coghlan, David and Teresa Brannick. Doing Action Research in Your Own Organization. 4th edition ed. London: Sage, 2014.

Coughlan, Paul and David Coghlan. "Action Research for Operations Management." International Journal of Operations \& Production Management 22, no. 2 (2002): 220-240.

Council, Construction Industry. No Title, 2005.

Cox, Andrew. "Sourcing Portfolio Analysis and Power Positioning: Towards a Paradigm Shift $\square$ in Category Management and Strategic Sourcing." Supply Chain Management: An International Journal (2015). doi:10.1108/SCM-06-2015-0226.

Daly, Shawn P. and Prithwiraj Nath. "Reverse Auctions for Relationship Marketers." Industrial Marketing Management 34, no. 2 (2005): 157-166. doi:10.1016/j.indmarman.2004.07.013.

Dixit, Avinash K. and Susan Skeath. Games of Strategy. New York: Norton, 1999.

Dutta, Prajit K. Strategies and Games: Theory and Practice. Boston: MIT Press, 1999.

Eden, Colin and Chris Huxham. "Action Research for Management Research." British Journal of Management 7, no. 1 (1996): 75-86. doi:10.1111/j.14678551.1996.tb00107.x.

Emiliani, M. L. and D. J. Stec. "Commentary on "Reverse Auctions for Relationship Marketers" by Daly and Nath." Industrial Marketing Management 34, no. 2 (2005): 167-171. doi:10.1016/j.indmarman.2004.09.007.

Engelbrecht-Wiggans, Richard and Elena Katok. "E-Sourcing in Procurement: Theory and Behavior in Reverse Auctions with Noncompetitive Contracts." Management Science 52, no. 4 (2006): 581-596.

Ferreira, Luís Miguel, Amílcar Arantes, and Alexander A. Kharlamov. "Development of a Purchasing Portfolio Model for the Construction Industry: An Empirical Study." Production Planning \& Control 26, no. 5 (2015): 377-392. doi:10.1080/09537287.2014.906679.

Fugger, Nicolas, Elena Katok, and Achim Wambach. "Trust in Procurement Interactions." Management Science 65, no. 11 (2019): 5110-5127. doi:10.1287/mnsc.2018.3196. 
G. Hawkins, Timothy, Wesley S. Randall, Adam V. Coyne, and Mohammad H.

Baitalmal. "Sustainable Integrity: How Reverse Auctions can Benefit Suppliers in Emerging Markets." Supply Chain Management: An International Journal 19, no. 2 (2014): 126-141.

Gale, John, Kenneth G. Binmore, and Larry Samuelson. "Learning to be Imperfect: The Ultimatum Game." Games and Economic Behavior 8, no. 1 (1995): 56-90. doi:10.1016/S0899-8256(05)80017-X.

Gelderman, Cees J. and Arjan J. Van Weele. "Handling Measurement Issues and Strategic Directions in Kraljic's Purchasing Portfolio Model." Journal of Purchasing and Supply Management 9, no. 5 (2003): 207-216.

. "Purchasing Portfolio Models: A Critique and Update." Journal of Supply Chain Management 41, no. 3 (2005a): 19-28.

"XXX Purchasing Strategies in the Kraljic matrix-A Power and Dependence Perspective." Journal of Purchasing and Supply Management 11, no. 2 (2005b): 141-155.

Ghanbarizadeh, Arad, Jafar Heydari, Jafar Razmi, and Ali Bozorgi-Amiri. "A Purchasing Portfolio Model for the Commercial Construction Industry: A Case Study in a Mega Mall." Production Planning \& Control 30, no. 15 (2019): 12831304. doi:10.1080/09537287.2019.1612110.

Gibbons, Robert S. "An Introduction to Applicable Game Theory." The Journal of Economic Perspectives Vol. 11, no. No. 1. (1997): 127-149.

Giunipero, Larry C., Samantha Bittner, Ilana Shanks, and Mee Hee Cho. "Analyzing the Sourcing Literature: Over Two Decades of Research." Journal of Purchasing and Supply Management 25, no. 5 (2019): 100521. doi:10.1016/j.pursup.2018.11.001.

Hanák, Tomáš and Jana Šelih. "On-Line Reverse Auctions in Construction Industry." Gradevinar 69, no. 9 (2017): 821-830. doi:10.14256/JCE.1352.2015.

Handfield, Robert B. and Steven A. Melnyk. "The Scientific Theory-Building Process: A Primer using the Case of TQM." Journal of Operations Management 16, no. 4 (1998): 321-339.

Hawkins, Timothy G., Michael J. Gravier, and C. Michael Wittmann. "Enhancing Reverse Auction use Theory: An Exploratory Study." Supply Chain Management: An International Journal 15, no. 1 (2010): 21-42. doi:10.1108/13598541011018102.

Hawkins, Timothy G., Wesley S. Randall, and C. Michael Wittmann. "An Empirical Examination of Reverse Auction Appropriateness in B2B Source Selection." Journal of Supply Chain Management 45, no. 4 (2009): 55-71. 
Hsin Chang, Hsin, Yao-Chuan Tsai, and Che-Hao Hsu. "E-Procurement and Supply Chain Performance." Supply Chain Management: An International Journal 18, no. 1 (2013): 34-51.

Huang, Samuel H. and Harshal Keskar. "Comprehensive and Configurable Metrics for Supplier Selection." International Journal of Production Economics 105, no. 2 (2007): 510-523.

Huh, Woonghee Tim and Kun Soo Park. "A Sequential Auction-Bargaining Procurement Model." Naval Research Logistics 57, no. 1 (2010): 13-32.

Hvolby, H. -H, J. Trienekens, and K. Steger-Jensen. "Buyer-supplier Relationships and Planning Solutions." Production Planning and Control 18, no. 6 (2007): 487-496.

Jap, Sandy. "Online Reverse Auctions: Issues, Themes, and Prospects for the Future." Journal of the Academy of Marketing Science 30, no. 4 (2002): 506-525. doi:10.1177/009207002236925.

Jap, Sandy D. "An Exploratory Study of the Introduction of Online Reverse Auctions." Journal of Marketing 67, no. 3 (2003): 96-107. doi:10.1509/jmkg.67.3.96.18651.

Kang, Mingu, Paul Hong, Roman Bartnik, Youngwon Park, and Changsuk Ko. "Aligning Purchasing Portfolio Management with Sourcing Negotiation Styles." Management Decision 56, no. 11 (2018): 2341-2356. doi:10.1108/MD-09-20160662.

Karabağ, Oktay, Oktay Karabăg, Barış Tan, and Barış Tan. "An Empirical Analysis of the Main Drivers Affecting the Buyer Surplus in E-Auctions." International Journal of Production Research 57, no. 11 (2018): 1-31. doi:10.1080/00207543.2018.1536835.

Kasanen, Eero, Kari Lukka, and Arto Siitonen. "The Constructive Approach in Management Accounting Research." Journal of Management Accounting Research 5, (1993): 243.

Kim, Minkyun, Nallan C. Suresh, and Canan Kocabasoglu-Hillmer. "A Contextual Analysis of the Impact of Strategic Sourcing and E-Procurement on Performance." Journal of Business \& Industrial Marketing 30, no. 1 (2015): 1-16. doi:10.1108/JBIM-01-2012-0010.

Krause, Daniel R., Mark Pagell, and Sime Curkovic. "Toward a Measure of Competitive Priorities for Purchasing." Journal of Operations Management 19, no. 4 (2001): 497-512.

Maestrini, Vieri, Davide Luzzini, Abraham B. (Rami) Shani, and Filomena Canterino. "The Action Research Cycle Reloaded: Conducting Action Research Across Buyer-Supplier Relationships." Journal of Purchasing and Supply Management 22, no. 4 (2016): 289-298. 
Mandolini, Marco, Eugenia Marilungo, and Michele Germani. "A TCO Model for Supporting the Configuration of Industrial Plants." Procedia Manufacturing 11, (2017): 1940-1949. doi:10.1016/j.promfg.2017.07.339.

Maschler, M., E. Solan, and S. Zamir. Game Theory. New York: Cambridge University Press, 2013.

Mediavilla, Miguel, Carolina Bernardos, Kepa Mendibil, and Olga Rivera. "How to Improve Supplier Selection for Complex Items using Product Engineering: Perspectives from the Industry." Dyna 95, no. 3 (2020): 270-275. doi:10.6036/9240.

Mediavilla, Miguel, Kepa Mendibil, and Olga Rivera. "How to Negotiate with Dominant Suppliers? A Game-Theory Perspective from the Industry." Dirección $Y$ Organización 67, (2019): 37-45.

Milgrom, Paul R. and Robert J. Weber. "A Theory of Auctions and Competitive Bidding." Econometrica 50, no. 5 (1982): 1089-1122.

Mithas, Sunil and Joni L. Jones. "Do Auction Parameters Affect Buyer Surplus in EAuctions for Procurement?" Production and Operations Management Vol. 16, no. 4 (2007): 455-470.

Mithas, Sunil, Joni L. Jones, and Will Mitchell. "Buyer Intention to use InternetEnabled Reverse Auctions: The Role of Asset Specificity, Product Specialization, and Non-Contractibility." MIS Quarterly Vol. 32:4, no. 4 (2008): 705-724.

Monczka, Robert, Robert Handfield, Larry Giunipero, and James Patterson. Purchasing and Supply Chain Management. Boston: Cengage Learning, 2008.

Osborne, Martin J. and Ariel Rubinstein. A Course in Game Theory. Boston: MIT press, 1994.

Pearcy, Dawn, Larry Giunipero, and Andrew Wilson. "A Model of Relational Governance in Reverse Auctions." Journal of Supply Chain Management 43, no. 1 (2007): 4-15. doi:10.1111/j.1745-493X.2007.00023.x.

Pedraza-Acosta, Isabel, Alan Pilkington, and David Barnes. "Production Systems and Supplier Selection: A Multi-Phase Process Model." Production Planning \& Control 27, no. 9 (2016): 717-726.

Pham, Long, Jeffrey Teich, Hannele Wallenius, and Jyrki Wallenius. "Multi-Attribute Online Reverse Auctions: Recent Research Trends." European Journal of Operational Research 242, no. 1 (2015): 1-9. doi:10.1016/j.ejor.2014.08.043.

Ramkumar, M., Tobias Schoenherr, and Mamata Jenamani. "Risk Assessment of Outsourcing E-Procurement Services: Integrating SWOT Analysis with a Modified ANP-Based Fuzzy Inference System." Production Planning \& Control 27, no. 14 (2016): 1171-1190. doi:10.1080/09537287.2016.1190877. 
Reny, Philip J. "Common Belief and the Theory of Games with Perfect Information." Journal of Economic Theory 59, no. 2 (1993): 257-274.

doi:10.1006/jeth.1993.1017.

Schoenherr, Tobias. The Evolution of Electronic Procurement. 1st ed. 2019 ed. Cham: Palgrave Macmillan, 2019.

Schoenherr, Tobias, Sachin B. Modi, W. C. Benton, Craig R. Carter, Thomas Y. Choi, Paul D. Larson, Michiel R. Leenders, Vincent A. Mabert, Ram Narasimhan, and Stephan M. Wagner. "Research Opportunities in Purchasing and Supply Management." International Journal of Production Research 50, no. 16 (2012): 4556-4579. doi:10.1080/00207543.2011.613870.

Schulze-Horn, Ines, Niels Pulles, Holger Schiele, and Paul Scheffler. "Using Mechanism Design Theory in Negotiations to Improve Purchasing Performance." International Journal of Procurement Management 11, no. 6 (2018): 777-800. doi:10.1504/IJPM.2018.095658.

Seth, Dinesh and Subhash Rastogi. "Application of Vendor Rationalization Strategy for Manufacturing Cycle Time Reduction in Engineer to Order (ETO) Environment." Journal of Manufacturing Technology Management 30, no. 1 (2019): 261-290. doi:10.1108/JMTM-03-2018-0095.

Seth, Dinesh, Dinesh Seth, VSR Krishna Nemani, Shaligram Pokharel, and Abdulla Yaqoub Al Sayed. "Impact of Competitive Conditions on Supplier Evaluation: A Construction Supply Chain Case Study." Production Planning \& Control 29, no. 3 (2018): 217-235. doi:10.1080/09537287.2017.1407971.

Spina, Gianluca, Federico Caniato, Davide Luzzini, and Stefano Ronchi. "Past, Present and Future Trends of Purchasing and Supply Management: An Extensive Literature Review." Industrial Marketing Management 42, no. 8 (2013): 1202-1212.

Srai, Jagjit Singh and Harri Lorentz. "Developing Design Principles for the Digitalisation of Purchasing and Supply Management." Journal of Purchasing and Supply Management 25, no. 1 (2019): 78-98. doi:10.1016/j.pursup.2018.07.001.

Steiglitz, Kenneth. Snipers, Shills, \& Sharks: eBay and Human Behavior. New Jersey: Princeton University Press, 2007.

Stentoft Arlbjørn, Jan and Per Vagn Freytag. "Public Procurement Vs Private Purchasing: Is there any Foundation for Comparing and Learning Across the Sectors?" International Journal of Public Sector Management 25, no. 3 (2012): 203-220. doi:10.1108/09513551211226539.

Susman, Gerald I. and Roger D. Evered. "An Assessment of the Scientific Merits of Action Research." Administrative Science Quarterly 23, no. 4 (1978): 582-603.

Tadelis, Steven. "Public Procurement Design: Lessons from the Private Sector." International Journal of Industrial Organization 30, no. 3 (2012): 297-302. doi:10.1016/j.ijindorg.2012.02.002. 
Tassabehji, Rana. "Understanding E-Auction use by Procurement Professionals: Motivation, Attitudes and Perceptions." Supply Chain Management: An International Journal 15, no. 6 (2010): 425-437.

Tatsiopoulos, Ilias P. "Special Issue Editorial: Purchasing and E-Procurement." Production Planning \& Control 15, no. 7 (2004): 631-633.

Toktaş-Palut, Peral, Ecem Baylav, Seyhan Teoman, and Mustafa Altunbey. "The Impact of Barriers and Benefits of E-Procurement on its Adoption Decision: An Empirical Analysis." International Journal of Production Economics 158, (2014): 77-90. doi:10.1016/j.ijpe.2014.07.017.

Tunca, Tunay I. and Qiong Wu. "Multiple Sourcing and Procurement Process Selection with Bidding Events." Management Science 55, no. 5 (2009): 763-780.

Van Weele, Arjan J. Purchasing and Supply Chain Management: Analysis, Strategy, Planning and Practice. Andover: Cengage Learning EMEA, 2009.

Van Weele, Arjan J. and Erik M. Raaij. "The Future of Purchasing and Supply Management Research: About Relevance and Rigor." Journal of Supply Chain Management 50, no. 1 (2014): 56-72.

Vickrey, William. "Counterspeculation, Auctions, and Competitive Sealed Tenders." The Journal of Finance 16, no. 1 (1961): 8-37.

Vignali, Claudio and Mike Zundel. "The Marketing Management Process and Heuristic Devices: An Action Research Investigation." Marketing Intelligence \& Planning 21, no. 4 (2003): 205-219.

Wagner, Stephan M. and Andreas P. Schwab. "Setting the Stage for Successful Electronic Reverse Auctions." Journal of Purchasing and Supply Management 10, no. 1 (2004): 11-26.

Weber, Charles A., John R. Current, and W. C. Benton. "Vendor Selection Criteria and Methods." European Journal of Operational Research 50, no. 1 (1991): 2-18.

Weber, Charles A. and Lisa M. Ellram. "Supplier Selection using Multi- objective Programming: A Decision Support System Approach." International Journal of Physical Distribution \& Logistics Management (1993). doi:10.1108/09600039310038161.

Webster, Jane and Richard T. Watson. "Analyzing the Past to Prepare for the Future: Writing a Literature Review." MIS Quarterly (2002): xiii-xxiii.

Wyld, David C. "Current Research on Reverse Auctions: Part I-Understanding the Nature of Reverse Auctions and the Price and Process Savings Associated with Competitive Bidding." International Journal of Managing Value and Supply Chains 2, no. 3 (2011): 1-15. 
Yigin, I. H., H. Taşkin, I. H. Cedİmoglu, and B. Topal. "Supplier Selection: An Expert System Approach." Production Planning \& Control 18, no. 1 (2007): 16-24.

Yu, Seunghee, Abhay Nath Mishra, Anandasivam Gopal, Sandra Slaughter, and Tridas Mukhopadhyay. "E- Procurement Infusion and Operational Process Impacts in MRO Procurement: Complementary Or Substitutive Effects?" Production and Operations Management 24, no. 7 (2015): 1054-1070. doi:10.1111/poms. 12362. 